\title{
Association of Albumin to Creatinine Ratio with Severity of Coronary Artery Disease
}

\author{
LOHANI MD TAJUL ISLAM ${ }^{1}$,ABU SADIQUE ABDULLAH ${ }^{1}$, SARKER MD ALAUDDINALAZAD ${ }^{3}$, \\ MOHAMMAD JUBAYER ${ }^{4}$, MD. GAFFAR AMIN ${ }^{2}$, K M N SABAH ${ }^{2}$, MOHAMMAD ABDUR RAHMAN ${ }^{1}$, \\ MD. FAKHRUL ISLAM KHALED ${ }^{1}$, ASIF ZAMAN TUSHAR ${ }^{5}$, ABDUL WADUD CHOWDHURY ${ }^{2}$, \\ MOHAMMAD SAFIUDDIN ${ }^{1}$, ATM IQBAL HASAN ${ }^{1}$
}

${ }^{1}$ Department of Cardiology, Bangabandhu Sheikh Mujib Medical University (BSMMU), Dhaka, ${ }^{2}$ Department of Cardiology, Dhaka Medical College \& Hospital, Dhaka, ${ }^{3}$ General Practitioner, Munshiganj, ${ }^{4}$ Department of Microbiology, Dhaka Medical College \& Hospital, Dhaka, ${ }^{5}$ Department of Cardiology, National Institute of Cardiovascular Diseases (NICVD), Dhaka.

Address for Correspondence: Dr. Lohani Md Tajul Islam, Medical Officer, Department of Cardiology, Bangabandhu Sheikh Mujib Medical University (BSMMU), Dhaka, Email: lohanibsmmu@yahoo.com

\begin{abstract}
Coronary artery disease (CAD) is the most common cause of mortality and morbidity all over the world. It is also becoming a significant burden on healthcare service in Bangladesh. Atherosclerosis is the main pathology behind coronary artery disease. Endothelial dysfunction plays a crucial role in the process of atherosclerosis. Microalbuminuria (MA) is a reliable marker of endothelial dysfunction. This is why microalbuminuria is recognized as a simple marker of atherogenic milieu It was a cross sectional analytical study carried out in the department of Cardiology, Dhaka Medical College Hospital, Dhaka during the period of May, 2013 to April, 2014. After ethical consideration a total of 120 patients with IHD admitted in the department of Cardiology who fulfilled the inclusion and exclusion criteria and underwent coronary angiogram were taken as sampling population by purposive sampling. $1^{\text {st }}$ morning spot urine sample was taken for measurement of ACR.Microalbumnuria was measured by rate nephelometry using Behring protein analyzer. All the study subjects were placed into two groups according to ACR value (group I- positive urinary $A C R \geq 30 \mathrm{mg} / \mathrm{g}$ \& group II-Normal urinary ACR $<30 \mathrm{mg} / \mathrm{g}$ ). Angiographic severity of coronary artery disease was assessed by vessel score and stenosis score. Age and sex distribution of the subjects in two groups with MAand without MA were similar. No significant difference was observed between two groups with regard to smoking, dyslipidaemia, hypertension and family history of IHD. Prevalence of diabetes mellitus was significantly more in subjects with MA than without MA (60\% vs 33.9\%, p=0.006). All 40 patients of group I had significant CAD. 57(71.2\%) patients of group II had significant CAD and 23(28.8\%) patients had no significant CAD. The difference was highly significant ( $<0.001)$. Single vessel involvement was significantly more frequent in subjects of group II than group I (35.0\% vs15.0\%, $=0.022)$ Double vessel involvement was more in group I than group II, but the difference was not statistically significant (36.8\% vs $32.40 \%, p=0.641)$.Triple vessel involvement was significantly more frequent in subjects of group I than group II (50.0\% vs $10.7 \%, p<0.001)$. The mean stenosis score of group I was significantly higher than group II (95\% CI 4.966 to 2.809 , $p<0.001)$. The mean $\pm S D$ total coronary vessel score of group I was 16.60 \pm 4.75 with a range of 7.0-21.0 and mean $\pm S D$ total coronary vessel score of group II was 8.26 \pm 6.24 with a range of 0.0-21.0. The mean total score of group I wassignificantly higher than group II (95\% CI 10.558 to $6.117, p<0.001)$. Patient with microalbuminuria has more extensive and complex angiographic coronary artery disease compared to those without microalbuminuria.
\end{abstract}

Key words: ACR, CAD, Coronary angiographic severity.

Introduction:

Atherosclerotic coronary heart disease is the leading cause of death in developed world ${ }^{1}$. South Asians have a higher prevalence of CAD as compared with other ethnicities, with a higher rate at younger age $\mathrm{e}^{2,3}$. The term microalbuminurea (MA) is defined as urinary albumin levels of more than or equal to $30-300 \mathrm{mg} / 24$ hours in 24 hours urine collection or albumin-creatinine ratio (ACR) of $\geq 30-300 \mathrm{mg} / \mathrm{gm}$ creatinine in random spot urine sample. The measurement of albumin to creatinine ratio (ACR) in random spot urine has become a widely accepted clinical tool for assessing urinary albumin excretion ${ }^{4}$.

Microalbuminurea has been identified as an independent risk factor for determining both short and long term 
morbidity and mortality after myocardial infarction (MI) ${ }^{5}$. Beside this, some of the previous studies have shown that the risk attributed to MA is independent of all other risk factors of atherosclerosis ${ }^{6,7}$. It is observed that patient with microalbuminurea had a greater atherosclerosis burden in the form of multi vessels coronary artery disease than in patient without $\mathrm{it}^{8}$. Study in diabetic patients showed the co-relation between angiographic severity and microalbuminurea was significant ${ }^{9}$. In non diabetic patients also such similar study revealed the same findings ${ }^{8}$.

Microalbuminuria is a persistent, increased urinary excretion of albumin ${ }^{10}$. Epidemiologic and experimental data show that microalbuminuria is associated with an increased risk for cardiovascular mortality, cardiac abnormalities, cerebrovascular disease, and peripheral arterial disease (PAD) ${ }^{10}$. The cardiovascular mortality rate in elderly people with microalbuminuria is reported to be as high as 2.94 times that in nonmicroalbuminuric controls. It is increased even further in people with diabetes and microalbuminuria ${ }^{10,11}$.

Microalbuminurea is a reliable marker of endothelial dysfunction. So measurement of MA can be taken as a non invasive method for early detection of atherosclerosis as well as its severity. Although, 24-h urine collection is the gold standard for the detection of MA, several studies have found that albumin to creatinine ratio is equally sensitive and specific and can be easily utilized on a daily basis. Non invasive methods for the prediction of the severity of Atherosclerosis lesions have become an important objective for early treatment as well as primary preventive measure. This study is intended to observe Albumin to creatinine ratio as a new predictor to assess the severity of coronary artery disease. This information will help in the management and preventive strategy of CAD in Bangladesh

\section{Materials and Methods:}

This Cross-sectional analytical study was conducted in the Department of Cardiology, Dhaka Medical College Hospital (DMCH), Dhaka for a period of one year from May, 2013 to April, 2014. One hundred twenty patients admitted with IHD in the department of Cardiology, who went coronary angiography for IHD were enrolled in this study.

\section{Exclusion criteria were}

Patients having liver insufficiency, renal insufficiency or recent UTI or any patients referred for CAG other than $\mathrm{CAD}$ (congenital heart disease and valvular heart disease) or patients with history of CABG or PCI or those who had participated in weight-reducing programs or having any other serious co-morbid condition.

\section{Study procedure}

Initial evaluation of the patients by history and clinical examination were performed and recorded in the preformed data collection sheet. Demographic profile and pulse, BP, body weight and BMI were measured. Risk factors for IHD like HTN, DM, smoking, dislipidaemia, obesity and family history of premature coronary artery disease were noted. Base line laboratory investigation that is e.g. CBC, CXR, serum creatinine, serum electrolytes, fasting blood sugar, fasting lipid profile, ECG, Echocardiography were done. First morning spot urine sample was taken for measurement of ACR. Miicroalbumnuria was measured by rate nephelometry using Behring protein analyser. Urine Albumin creatinine ratio (ACR) was calculated and reported as $\mathrm{mg} / \mathrm{g}$ creatinine. Coronary angiogram was done by transfemoral route by Judkins method. Interpretation of coronary angiogram was reviewed and angiographic severity of coronary artery disease was assessed by vessel score and stenosis score.

\section{Results and Observations:}

In this study, 120 patients admitted for coronary angiography for CAD detection were included.

According to the level of urinary ACR the patients were divided into two groups, group I consisted of patients with ACR level $\geq 30 \mathrm{mg} / \mathrm{g}$ (positive urinary ACR) and group II consisted of patients with ACR level $<30 \mathrm{mg} / \mathrm{g}$ (normal urinary ACR) (Figure-1).
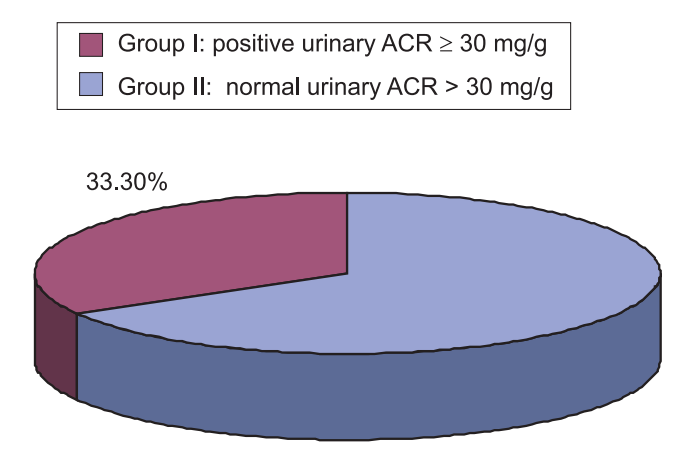

$66.70 \%$

Fig.-1: Frequency of microalbuminuria among the study subjects. 
No significant difference was observed between two groups with regard to smoking ( $25 \%$ vs $22.5 \%$, $\mathrm{p}=0.76$ ), dyslipidaemia ( $20 \%$ vs $16.2 \%$, $\mathrm{p}=0.61$ ), hypertension $(55 \%$ in both two groups, $\mathrm{p}=1.00)$ and family history of IHD ( $0 \%$ vs $2.5 \%, \mathrm{p}=0.31$ ). The prevalence of diabetes mellitus was significantly more in subjects of group I than group II (60\% vs $33.9 \%$, $\mathrm{p}=0.006$ ) (Table- $\mathrm{I}$ ).

All 40 patients of group I had significant CAD. 57 (71.2\%) patients of group II had significant CAD and 23 (28.8\%) patients had no significant CAD. The difference was highly significant $(\mathrm{p}<0.001)$ (Table- II).

Twenty (25\%) patients of group II had no CAD in angiography. No patients of group I had normal vessel. The difference was statistically significant $(\mathrm{p}=0.001)$. Single vessel involvement was more frequent in group II than group I ( $35 \%$ vs $15 \%$, $\mathrm{p}=0.022$ ). Double vessel involvement was more in group I than group II, but the difference was not statistically significant ( $36.8 \%$ vs $32.4 \%, \mathrm{p}=0.641$ ). Triple vessel involvement was significantly more frequent in subjects of group I than group II (50.0\% vs $10.7 \%$, $\mathrm{p}<0.001$ ) (Table- III).

The mean \pm SD stenosis score of group I was 7.20 \pm 3.28 with a range of 3-180 and the mean \pm SD stenosis score of group II was $3.31 \pm 2.55$ with a range of $0-9$. The mean stenosis score of group I was significantly higher than group II (95\% CI 4.96 to $2.80, \mathrm{p}<0.001)$. The mean \pm SD total coronary vessel score of group I was $16.60 \pm 4.75$ with a range of 7-21 and mean \pm SD total coronary vessel score of group II was $8.26 \pm 6.24$ with a range of $0-21$. The mean total score of group I was significantly higher than group II (95\% CI 10.55 to 6.11, p<0.001) (Table- IV).

Table-V shows multiple logistic regression analysis of triple vessel disease with independent risk factors. The independent variable microalbuminuria was significantly associated with triple vessel disease $(\mathrm{B}=2.349, \mathrm{OR}=10.472$, $\mathrm{p}<0.001)$. Smoking and diabetes mellitus were also significantly associated with triple vessel disease $(\mathrm{p}=0.011$ and 0.028 respectively).

Table-I

Comparison of traditional risk factors between two study groups $(n=120)$

\begin{tabular}{lcccc}
\hline Traditional risk factor & Group-É $\left(\mathrm{n}_{1}=40\right)$ & Group-ÉÉ $\left(\mathrm{n}_{2}=80\right)$ & P value & \\
\hline Smoking & Present & $10(25.0)$ & $18(22.5)$ & $0.760^{\mathrm{NS}}$ \\
& Absent & $30(75.0)$ & $62(77.5)$ & \\
Diabetes mellitus & Present & $24(60.0)$ & $27(33.9)$ & $0.006^{\mathrm{S}}$ \\
& Absent & $16(40.0)$ & $53(66.2)$ & \\
Dyslipidaemia & Present & $8(20.0)$ & $13(16.2)$ & $0.610^{\mathrm{NS}}$ \\
& Absent & $32(80.0)$ & $67(83.8)$ & \multirow{2}{*}{$1.000^{\mathrm{NS}}$} \\
Hypertension & Present & $22(55.0)$ & $44(55.0)$ & \\
& Absent & $18(45.0)$ & $36(45.0)$ & \multirow{2}{*}{$0.313^{\mathrm{NS}}$} \\
Family history of IHD & Present & $0(0.0)$ & $2(2.5)$ & \\
& Absent & $40(100.0)$ & $78(97.5)$ & \\
\hline
\end{tabular}

$\mathrm{S}=$ significant, NS=not significant

Table-II

Comparison of significant CAD between two study groups $(n=120)$

\begin{tabular}{lcc}
\hline Severity of CAD & Group I $\left(\mathrm{n}_{1}=40\right)$ & ${\text { Group II }\left(\mathrm{n}_{2}=80\right)}$ \\
\hline Significant CAD & $40(100.0)$ & $57(71.2)$ \\
No significant CAD & $0(0.0)$ & $23(28.8)$ \\
S=Significant & & \\
\hline
\end{tabular}

Table-III

Comparison of number of diseased vessels (extent of CAD) between two study groups ( $n=120)$

\begin{tabular}{lcc}
\hline Number of vessels diseased & Group I $\left(\mathrm{n}_{1}=40\right)$ & Group II $\left(\mathrm{n}_{2}=80\right)$ \\
\hline No diseased vessel & $0(0.0)$ & $20(25.0)$ \\
Single vessel & $6(15.0)$ & $28(35.0)$ \\
Double vessel & $14(36.8)$ & $24(32.4)$ \\
Triple vessel & $20(50.0)$ & $8(10.7)$ \\
\hline
\end{tabular}

NS=not significant, S=Significant 
Table-IV

Comparison of stenosis score and total coronary vessel score (ie severity of CAD) between the study groups $(n=120)$.

\begin{tabular}{lccc}
\hline Stenosis score & $\begin{array}{c}\text { Group I }\left(\mathrm{n}_{1}=40\right) \\
\text { Mean } \pm \operatorname{SD} \text { (Range) }\end{array}$ & $\begin{array}{c}\text { Group II }\left(\mathrm{n}_{2}=80\right) \\
\text { Mean } \pm \operatorname{SD}(\text { Range })\end{array}$ & P value \\
\hline Stenosis score & $7.20 \pm 3.283-180$ & $3.31 \pm 2.550-9$ & $<0.001^{\mathrm{S}}$ \\
Total coronary vessel score & $16.60 \pm 4.757-21$ & $8.26 \pm 6.240-21$ & $<0.001^{\mathrm{S}}$ \\
\hline
\end{tabular}

S=Significant

Table-V

Multiple Logistic regression analysis of disease severity with independent risk factors

\begin{tabular}{lccccc}
\hline Independent risk factors & B & P value & Exp(B) & \multicolumn{2}{c}{ 95\% CI for Exp(B) } \\
& & & & Lower Bound & Upper Bound \\
\hline Age & -0.135 & 0.816 & 0.874 & 0.280 & 2.726 \\
Sex & 1.017 & 0.215 & 2.765 & 0.554 & 13.806 \\
Smoking & -2.011 & 0.011 & 0.134 & 0.029 & 0.627 \\
Hypertension & 1.112 & 0.056 & 3.040 & 0.974 & 9.492 \\
Diabetes mellitus & 1.321 & 0.028 & 3.747 & 1.154 & 12.164 \\
Dyslipidaemia & -1.829 & 0.064 & 0.161 & 0.023 & 1.113 \\
Microalbuminuria & 2.349 & 0.000 & 10.472 & 3.194 & 34.327 \\
\hline
\end{tabular}

$\mathrm{B}=$ Coefficient, $\operatorname{Exp}(\mathrm{B})=$ Estimated odds ratio $(\mathrm{OR}), \mathrm{p}$ value= level of significance, $95 \% \mathrm{CI}=$ Confidence interval for $\operatorname{Exp}(\mathrm{B})$

\section{Discussion:}

Microalbuminuria is the presence of albumin in urine above the normal range but below the detectable range with conventional dipstick methodology (30-300 mg/d) or urinary albumin creatinine ratio $30-300 \mathrm{mg} / \mathrm{g}$ in spot urine sample ${ }^{12}$. Urinary ACR in spot urine sample was used to detect MA as it was shown to be equally sensitive and specific to 24h urine collection method ${ }^{13}$.

A total of 120 patients with IHD were recruited in this study who underwent coronary angiography. Forty of them had microalbuminuria and were classified as group I and 80 did not have microalbuminuria, and were classified as group II. Both the groups were similar in terms of age and sex. No significant difference were observed between these two groups in other traditional risk factors except diabetes mellitus, the prevalence of which was significantly more in group I than in group II (60.0\% vs 33.9\%, p=.006).

Several studies have shown the association between microalbuminuria and extent of coronary disease ${ }^{9,14-18}$. In this present study all patients with microalbuminuria had significant CAD. Whereas, 57 (71.2\%) patients with no microalbuminuria had significant CAD and 23(28.8\%) patients had no significant CAD. The difference was statistically highly significant. This finding coincides with the study of Hoseini and Rasouli who found that microalbuminuria was more prevalent in CAD-positive patients than in controls $(62.9 \% \text { vs. } 8.8 \%)^{15}$. Sadaka et al correlated between MA and severity of CAD among patients with documented CAD by coronary angiography. They found a direct relationship between MA and extension of atherosclerotic coronary lesions $(\mathrm{p}=0.009)$ which also is in accordance with this present study ${ }^{14}$. In the study conducted by Parvizi et al it was observed that there is a direct relationship between microalbuminuria and extension of atherosclerotic coronary lesions. It was concluded that microalbuminuria may in fact be a indicator of cardiovascular events ${ }^{16}$.

The mean stenosis score and the mean total coronary vessel score of the subjects of group I was significantly higher than subjects of group II $(\mathrm{p}<0.001)$. Triple vessel involvement was significantly more frequent in subjects with positive ACR (group I) than subjects with normal ACR (group II) (50\% vs $10.7 \%, \mathrm{p}<0.001$ ) which was also justified by multiple logistic regression analysis $(\mathrm{p}<0.001)$. This findings correlate with a study in Bangladesh conducted by Reza et al who investigated the relationship of microalbuminuria and angiographic severity of coronary artery disease ${ }^{18}$. They found that all parameters of angiographic severity were significantly higher in microalbuminuric patients. Significant positive correlation 
between albumin to creatinine ratio and different parameters of angiographic severity was observed. In multivariate logistic regression analysis odds ratio of having triple vessel coronary artery disease in microalbuminuric patients was 5.6 (95\% CI, 1.4-22). It was concluded that microalbuminuria correlated positively and independently with angiographic severity of coronary artery disease ${ }^{18}$.

It was found that only triple vessel; neither single nor double vessel involvement was significantly associated with microalbuminuria. This observation was not in agreement with Hoseini and Rasouli (2009). They found that patients with microalbuminuria compared with the controls had increased prevalence of one $(\mathrm{p}<0.001)$, two $(\mathrm{p}<0.001)$, and three vessel disease $(\mathrm{p}<0.001)^{15}$.

Tuttle et al (1999) found that the urinary excretion of albumin increased progressively with severity of CAD and they were more pronounced in patients with diabetes. In multiple regression analysis, the odds ratios for severe CAD were 2.2 for microalbuminuria ${ }^{19}$.

Though the hypothesis of microalbuminuria as an atherosclerotic risk factor stems from diabetic research, several studies have now demonstrated that MA is an independent predictor of cardiovascular morbidity and mortality in non diabetic populations as well. It has been postulated that MA is a marker of generalized endothelial dysfunction ${ }^{20}$.

\section{Ethical consideration}

The research protocol was approved by the Research Review Committee of the Department of Cardiology and the Ethical Review Committee of DMCH. The aims and objectives of the study along with procedure, alternative diagnostic method, risk and benefits were explained to the patients and then informed written consent was taken from them. It was made clear to the participants before question answering session that who did not want to participate in the study should feel free to withdraw. The anonymity of the participants and confidentially of information was maintained strictly.

\section{Financial support:}

The work was supported financially by the department of cadiology, Dhaka Medical College Hospital, Dhaka, Bangladesh.

\section{Conflict of interest:}

We do not have any potential conflicts of interest.

\section{Referrence:}

1. Michaud CM, Murray CJ, Bloom BR. Burden of diseaseimplication for further research. JAMA 2001; 285: 535-9.

2. Yusuf S, Reddy S, Ounpuu S, Anand S. Global burden of cardiovascular diseases: part II: variations in cardiovascular disease by specific ethnic groups and geographic regions and prevention strategies. Circulation 2001; 104(23): 2855-64.

3. Bhopal R. What is the risk of coronary heart disease in South Asians? A review of UK research. J Pub Health Med 2000; 22(3): 375-85.

4. Ginsberg JM, Chang BS, Matarese RA, Garella S. Use of single voided urine samples to estimate quantitative proteinuria. $\mathrm{N}$ Engl J Med 1983; 309(25): 1543-6.

5. Berton G, Cordiano R, Mazzuco S. Albumin excretion in acute myocardial infarction: a guide for long-term prognosis. Am Heart J 2008; 156: 760-8.

6. Morgan

7. Mattock M, Morrish NJ, Viberti G, Keen H, Fitzgerald AP, Jackson G. Prospective study of microalbuminuria as predictor of mortality in NIDDM. Diabetes 1992; 41: 736-41.

8. Hoseinii VN and Tazaki O. Relationship between Microalbuminuria and severity of coronary artey disease in non-diabetic patients. Iran Cardiovasc Res J 2008; 4: 234-7.

9. Sukhija R, Aronow WS, Kakar P, et al. Relation of microalbuminuria and coronary artery disease in patients with and without diabetes mellitus. Am J Cardiol 2006; 98(3): 279-81.

10. Weir MR. Microalbuminuria and cardiovascular disease. Clin J Am Soc Nephrol 2007; 2: 581-90.

11. Kashif W, Siddiqi N, Dincer HE, Dincer AP, Hirsch S. Proteinuria: how to evaluate an important finding. Cleveland Clin J Med 2003; 70: 535-47.

12. Khosla N, Sarafidis PA, Bakris GL. Microalbuminuria. Clin Lab Med 2006; 26: 635-53.

13. Eknoyan G, Hostetter T, Bakris GL, et al. Proteinuria and other markers of chronic kidney disease. Am J Kidney Dis 2003; 42(4): 617-22.

14. Sadaka M. Albumin to creatinine ratio as a predictor to the severity of coronary artery disease. Alex J Med 2013; 49: 323-8.

15. Hoseini VN and Rasouli M. Microalbuminuria correlates with the prevalence and severity of coronary artery disease in non-diabetic patients. Cardiol J 2009; 16: 142-5.

16. Parvizi R, Rahbani M, Salmasi SH, Safavi M. Relationship between Microalbuminuria and extent of coronary atherosclerotic lesions. Iranian Heart J 2005; 6: 20-5.

17. Li-xin G, Jing M, Yang C, Li-na Z, Ming L. Urinary albumin excretion rate is correlated with severity of coronary artery disease in elderly type 2 diabetic patients. Chin Med J 2012; 125(23): 4181-4.

18. Reza AS, Zaher A, Reza AQ, Ali M. Correlation between microalbuminuria and angiographic severity of coronary artery disease. BMRC Bull 2006; 32: 78-86.

19. Tuttle KR, Puhlman ME, Cooney SK, Short R. Urinary albumin and insulin as predictors of coronary artery disease: An angiographic study. Am J Kidney Dis 1999; 34(5): 918-25.

20. Hashim R, Nisar S, Rehman K, Naqi N. Microalbuminuria: association with ischaemic heart disease in non-diabetics. J Ayub Med Coll Abbottabad 2006; 18: 1-4. 